Check for updates

Cite this: RSC Adv., 2017, 7, 39172

\title{
A conductive carbon interlayer modified by magnetron sputtering for improved-performance lithium-sulfur batteries
}

\author{
Jing Zhang, (D) ab Heqin Li, ${ }^{\text {b }}$ Zhiwei Lin, ${ }^{\text {b }}$ Qiong Tang, ${ }^{\text {ab }}$ Weiyu Qi, ${ }^{\text {b }}$ Lulu Wang, ${ }^{\text {b }}$ \\ Hao Zheng ${ }^{b}$ and Kuan Zhou ${ }^{b}$
}

\begin{abstract}
Cathode materials (S-AC) for lithium-sulfur ( $\mathrm{Li}-\mathrm{S}$ ) batteries were synthesised with elemental sulfur (S) and activated carbon (AC). Conductive carbon films (CF1) were prepared with filter paper and aluminum (Al) thin films were plated onto the surface of the filter paper by the method of magnetron sputtering to fabricate modified carbon films (CF2). The as-prepared carbon films were applied as conductive interlayers inserted between the cathode and the separator for Li-S batteries S/AC/CF1 and S/AC/CF2. The properties of the cathode materials and the carbon interlayers were characterized by XRD and FESEM. Electrochemical performances of three Li-S batteries with and without interlayers (S/AC/CF1, S/AC/CF2 and $\mathrm{S} / \mathrm{AC}$ ) were determined by alternating-current impedance, cyclic voltammetry and constant-current charge and discharge. The assessment results show that S/AC/CF2 is superior to the others with an initial discharge specific capacity of $1273 \mathrm{~mA} \mathrm{~h} \mathrm{~g}^{-1}$ at a current rate of $1 \mathrm{C}$. It delivered a reversible capacity of $924 \mathrm{~mA} \mathrm{~h} \mathrm{~g}^{-1}$ after 100 cycles and the coulombic efficiency after 200 cycles is still over $95 \%$.
\end{abstract}

Received 7th May 2017

Accepted 21st July 2017

DOI: 10.1039/c7ra05136k

rsc.li/rsc-advances delivered reversible capacities of $962 \mathrm{~mA} \mathrm{~h} \mathrm{~g}^{-1}$ after 50 cycles at $0.2 \mathrm{C}$ rate. $\mathrm{Li}^{\mathbf{1 9}}$ fabricated an effective interlayer based on direct pyrolysis of cellulose paper for $\mathrm{Li}-\mathrm{S}$ batteries which provided a discharge capacity higher than $830 \mathrm{~mA} \mathrm{~h} \mathrm{~g}^{-1}$ and an efficiency over $97 \%$ at $0.2 \mathrm{C}$.

The vast majority of research work lay emphasis on the modification of Li-S batteries by chemical process, nevertheless there is little attention paid to the innovation of $\mathrm{Li}-\mathrm{S}$ batteries by physical methods, for example, the magnetron sputtering technique. As an developed and mature method of physical vapor deposition, magnetron sputtering has been widely applied to prepare metal, alloy and semiconductor materials on account of the merits of high rate, low temperature, good compactness and excellent adhesion between the substrates and thin films..$^{20,21}$ As is reported, Zhang and coworkers $^{22}$ have adopted the technique to the modification of cathode materials of lithium-sulfur batteries and a superior performance was acquired. $\mathrm{Hu}^{23}$ has utilized magnetron sputtering to prepare improved-performance all-solid lithium-sulfur batteries. In this experiment, conductive carbon films were prepared with filter paper and Al particles were deposited onto the surface of filter paper by the method of radio-frequency magnetron sputtering to obtain conductive interlayers for Li-S batteries (Fig. 1). Comparison between the batteries with and without the modified carbon interlayers was carried out to confirm the assumption that a conductive carbon interlayer may be a key to mitigate the shuttle effect and improve the cycling stability.
${ }^{a}$ School of Electronic Science and Applied Physics, Hefei University of Technology, No. 193 Tunxi Road, Hefei, Anhui 230009, People's Republic of China.E-mail: Ihqjs@hfut. edu.cn; Fax: +86-0551-62901362; Tel: +86-0551-62901362

${ }^{b}$ School of Materials Science and Engineering, Hefei University of Technology, Hefei, Anhui 230009, People's Republic of China 


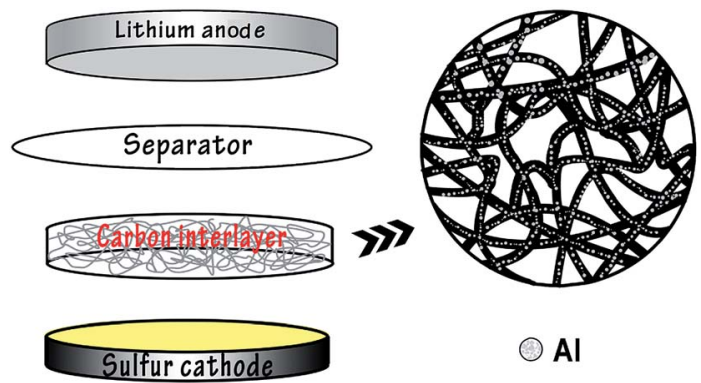

Fig. 1 Structure of the modified Li-S battery with a carbon interlayer.

\section{Experimental details}

\subsection{Preparation of S-AC cathode materials}

Elemental sulfur and activated carbon (pore diameter 2.0$2.2 \mathrm{~nm}$, specific surface area $1800 \mathrm{~m}^{2} \mathrm{~g}^{-1}$, JCNANO, Nanjing) were mixed with mass ratio of $4: 1$, then grinded adequately in an agate mortar. The mixture was heated in a two-step way in a vacuum tubular furnace under flowing Ar atmosphere: firstly heated to $155{ }^{\circ} \mathrm{C}$ and kept for $6 \mathrm{~h}$ to make the sulfur melt fully and spread into the interspace of carbon particles, then raised to $300{ }^{\circ} \mathrm{C}$ and kept for $1 \mathrm{~h}$ so that the residual elemental sulfur on the AC surface could be removed. Finally, the mixture was cooled to room temperature. The as-prepared composite was mixed with acetylene black $(\mathrm{AB})$ as conductive additive, polyvinylidene fluoride (PVDF) as adhesive and $N$-methyl-2pyrrolidone (NMP) as solvent to synthesize cathode material $\mathrm{S}-\mathrm{AC}$, with the mass ratio of composite, AB and PVDF $7: 2: 1$. The mixture was fully grinded to black slurry and uniformly coated onto the $\mathrm{Al}$ foil with the scraper. After being fully dried at $60{ }^{\circ} \mathrm{C}$ for $6 \mathrm{~h}$ and pressed by twin screw roller press, the coated $\mathrm{Al}$ foil was cut into circular electrode slices with diameter 14 $\mathrm{mm}$, sulfur content $0.86 \mathrm{mg} \mathrm{cm}^{-2}$, and placed in $50{ }^{\circ} \mathrm{C}$ vacuum oven.

\subsection{Magnetron sputtering deposition of Al}

Filter paper was cut into circular slices with about $5 \mathrm{~cm}$ diameter to match the sample holders of the magnetron sputtering apparatus, immersed in ethanol and cleaned with ultrasonic washer for $15 \mathrm{~min}$, then put into the air dry oven of $50^{\circ} \mathrm{C}$. After being fully dried, the slices were placed into the vacuum chamber of the ultrahigh vacuum magnetron sputtering equipment (FJL560B1, SKY Technology Development Co., Ltd. Chinese Academy of Sciences). Tiny Al particles were deposited onto the surface of filter paper slices by radio-frequency magnetron sputtering with pure Al targets (purity 99.99\%) at room temperature. The base pressure of sputtering chamber was $1.0 \times 10^{-4} \mathrm{~Pa}$ and the deposition was carried out in $\mathrm{Ar}$ atmosphere (purity 99.99\%) with the flow rate of $20 \mathrm{~mL} \mathrm{~min} \mathrm{~m}^{-1}$ measured accurately by the gas mass flowmeter (D08-3B/ZM, Beijing Sevenstar Huachuang Electronics Co. Ltd.). Presputtering for the Al target was conducted for 15 min before deposition in order to remove the impurities on the surface of the target. The sputtering pressure was $1.0 \mathrm{~Pa}$, power $25 \mathrm{~W}$, and sputtering time $7 \mathrm{~min}$. The sample holders rotated at a constant speed during sputtering in order to obtain a homogeneous thin film of Al.

\subsection{Preparation of conductive carbon interlayers}

After the sputtering was accomplished, the filter paper coated with $\mathrm{Al}$ thin film was taken out and placed in vacuum tube oven, slowly heated to $800{ }^{\circ} \mathrm{C}$ and kept for $2 \mathrm{~h}$ in flowing $\mathrm{Ar}-\mathrm{H}_{2}$ gas mixture and then cooled to room temperature to fulfill the carbonizing process. The carbonized filter paper was cut into circular slices with $14 \mathrm{~mm}$ diameter and placed in $50{ }^{\circ} \mathrm{C}$ vacuum oven, labeled as CF2. Carbon films without $\mathrm{Al}$ were prepared with filter paper by the same carbonizing method and labeled as CF1.

\subsection{Battery assembly}

CR-2032 coin cells were assembled in dry glove box (volume fractions of $\mathrm{H}_{2} \mathrm{O}$ and $\mathrm{O}_{2}$ less than $0.1 \times 10^{-6}$, Etelux Lab2000) filled with $\mathrm{Ar}$, cathode material S-AC as working electrodes, lithium as counter electrode, Celgrad 2400 membrane as separator and $1 \mathrm{~mol} \mathrm{~L}^{-1}$ lithium bis(trifluoromethanesulphonyl)imide (LiTFSI)/1,2-dimethoxyethane (DME) + 1,3-dioxolane (DOL) (volume ratio $1: 1$ ) as electrolyte, including $1.0 \% \mathrm{LiNO}_{3}$ as an electrolyte additive. Carbon films CF1 and CF2 were placed respectively between the cathode and the separator and the cells were labeled as S/AC/CF1 and S/AC/ $\mathrm{CF} 2$. The contents of $\mathrm{Al}$ on the filter paper and CF2 were measured to be $1.89 \%$ and $2.26 \%$, as well as the electrical resistivity of CF1 $8.47 \times 10^{-2} \Omega \mathrm{cm}$ and CF2 $3.92 \times 10^{-2} \Omega \mathrm{cm}$ respectively. Coin cells $\mathrm{S} / \mathrm{AC}$ without carbon films were also assembled for comparison.

\subsection{Material characterization and electrochemical performance testing}

$\mathrm{X}$-Ray diffractometer (X'-pert PROPA Nalytical, Netherlands) was employed to analyse the structures of sublimed S, AC and S-AC cathode material with $\mathrm{Cu} \mathrm{K} \alpha$ source $(\lambda=1.542 \AA)$. The working voltage was $40 \mathrm{kV}$ and the operating current was $40 \mathrm{~mA}$, scanning continuously from $5^{\circ}$ to $85^{\circ}$ with the rate of $8^{\circ} \mathrm{min}^{-1}$. Field emission scanning electron microscope (FESEM, Hitachi SU8020) were used to characterize the morphologies of cathode material and carbon films as well as the distribution of S, C and Al. Cyclic voltammetry and alternating-current impedance were obtained on the electrochemical workstation (CHI604D, Shanghai Chenhua). The scanning voltage was ranged from $1.5 \mathrm{~V}$ to $3.0 \mathrm{~V}$ and scanning speed was $0.1 \mathrm{mV} \mathrm{S}^{-1}$. The alternating-current impedance frequency was ranged from $10^{-2} \mathrm{~Hz}$ to $10^{5} \mathrm{~Hz}$ with the amplitude of $\pm 5 \mathrm{mV}$. Constant current charge-discharge tests were performed on the battery performance testing system (NEWARE BTS3000).

\section{Results and analysis}

Fig. 2 is the XRD patterns of AC, elemental $S$ and the cathode material. The amorphous AC show low and broad peaks at about $21^{\circ}$ and $43^{\circ}$ while elemental $S$ presents three 

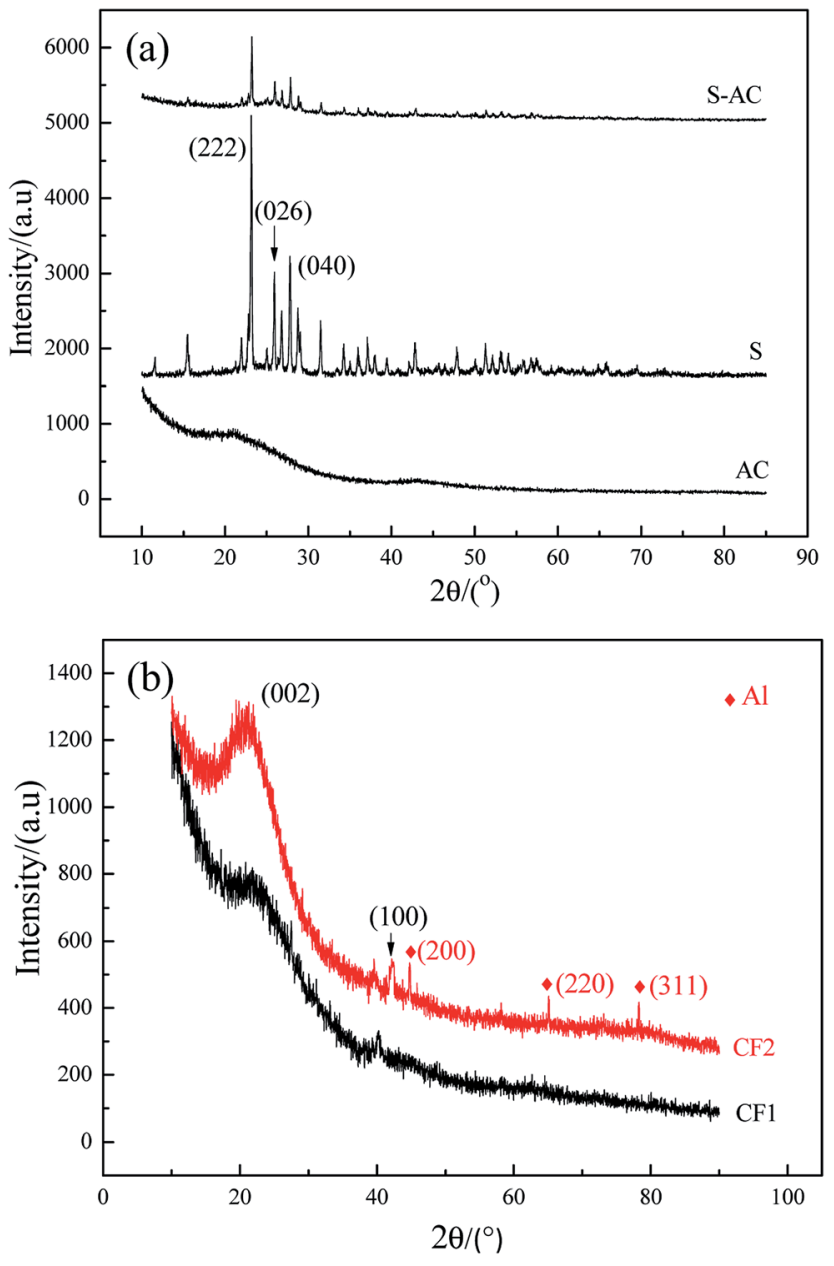

Fig. 2 XRD patterns of (a) AC, S and S-AC cathode material and (b) CF1 and CF2.

characteristic peaks at about $23.1^{\circ}, 25.7^{\circ}$ and $27.3^{\circ}$ corresponding to the crystal faces (222), (026) and (040) of orthorhombic system. The diffractive peak intensity of S in $\mathrm{S}-\mathrm{AC}$ was obviously weakened, which was resulted from the adsorption of elemental S into AC. As shown in Fig. 2(b), CF1 is approximatively amorphous with two bread-peaks occurring around $23^{\circ}$ and $42^{\circ}$ while CF2 presents an evident tendency of graphitization at approximate location, anastomosing lattice planes of (002) and (100) respectively, ${ }^{24}$ which may be the consequence of catalytic graphitization mechanism of $\mathrm{Al}$ on the surface of $\mathrm{CF} 2 .^{25}$ The diffraction peaks of $\mathrm{Al}$ are located at $44.7^{\circ}, 65.1^{\circ}$ and $78.2^{\circ}$, consistent with the crystal faces of (200), (220) and (311). The graphitization structure of CF2 and the presence of Al may lead to better conductivity and consequently superior electrochemical properties of the Li-S battery.

Fig. 3 is the photographs of a filter paper slice and another one coated with Al film. After being fully carbonized, the slices appear black and dark grey respectively. Fig. 4 is FESEM patterns of S-AC cathode material and two kinds of carbon films. The conductive matrix AC has abundant interspace and large specific surface area, which will accommodate $\mathrm{S}$ and intermediate polysulfides. The distribution of S and C in S-AC

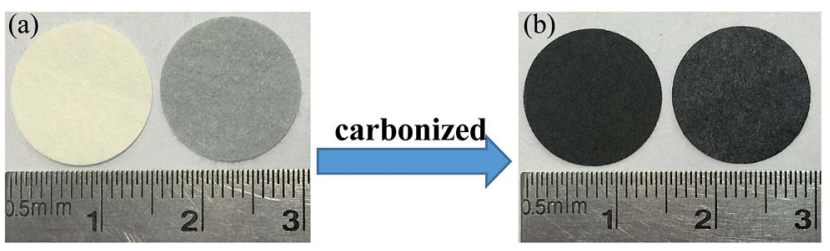

Fig. 3 Facade of (a) filter paper and (b) carbon films.

can be discerned from Fig. 4(b) and (c). Fig. 4(d) and (e) indicate that fibers in the carbon films twine and intersect with each other, making a stockade to intercept the polysulfides diffusing to the anode and mitigate the shuttle effect. Meanwhile the interspace between the fibers ensures good flexibility and mechanical strength of the carbon films and sufficient infiltration of the electrolyte. Consequently the conductive network of carbon interlayers can maintain intact in case sulfur or polysulfides precipitate out in the carbon films. Therefore the carbon interlayers promote electronic conductivity of the sulfur cathode as well as provide adequate room for the products of redox reaction. As far as the specific conductance $\left(3.54 \times 10^{7} \mathrm{~S} \mathrm{~m}^{-1}\right)$ of $\mathrm{Al}$ is concerned, $\mathrm{S} / \mathrm{AC} / \mathrm{CF} 2$ would benefit more from the excellent electronic conductivity of $\mathrm{CF} 2$ and advanced performances of the $\mathrm{Li}-\mathrm{S}$ batteries could be expected.

Fig. 5 demonstrates the electrochemical impedance spectroscopy before charge-discharge cycles. The first point of intersection of the semicircle in the high frequency region and abscissa axis denotes internal resistance of the batteries, which is probably determined by ionic resistance of electrolyte, intrinsic resistance of active materials and contact resistance at the interface of active material and current collector. ${ }^{26}$ The similar internal resistance of three samples reflects the approximately equal dynamics resistance of the electrochemical reaction taking place at the interface of electrode and electrolyte. ${ }^{27}$ Meanwhile the semicircle radiuses of the cells containing carbon interlayers are obviously less than that of S/AC, indicating improved charge-transfer resistance. Taking the resistivity of $\mathrm{Al}\left(2.83 \times 10^{-8} \Omega \mathrm{m}\right)$ into consideration, the presence of $\mathrm{Al}$ on the surface of CF2 improves the conductivity of S/AC/CF2 effectively, thereby in which the electrochemical reaction takes place with the highest rate. The slopes of the inclined short lines in low frequency region are both close to 1 , standing for the analogous diffusing ability of lithium ions in the solid phase. $^{28}$

The results of CV tests are presented in Fig. 6. For the three samples, two reduction peaks of CV curves appear at about 2.2$2.3 \mathrm{~V}$ and $1.9-2.0 \mathrm{~V}$ respectively. The former is corresponding to the process in which elemental $\mathrm{S}$ is reduced to soluble polysulfides with long chains $\left(\operatorname{Li}_{2} \mathrm{~S}_{n}, n \geq 4\right)$, controlled by chemical reaction mechanism, and the latter is corresponding to the diffusion-controlled process in which polysulfides with long chains are further reduced to insoluble polysulfides $\left(\mathrm{Li}_{2} \mathrm{~S}_{2}\right.$ and $\left.\mathrm{Li}_{2} \mathrm{~S}\right)$ with short chains $\left(\mathrm{Li}_{2} \mathrm{~S}_{n}, n<4\right)$. The oxidation peak is corresponding to the oxidation processes, in which insoluble $\mathrm{Li}_{2} \mathrm{~S}_{2}$ and $\mathrm{Li}_{2} \mathrm{~S}$ are firstly oxidized to polysulfides with long chains and further to elemental S. The reduction currents of 

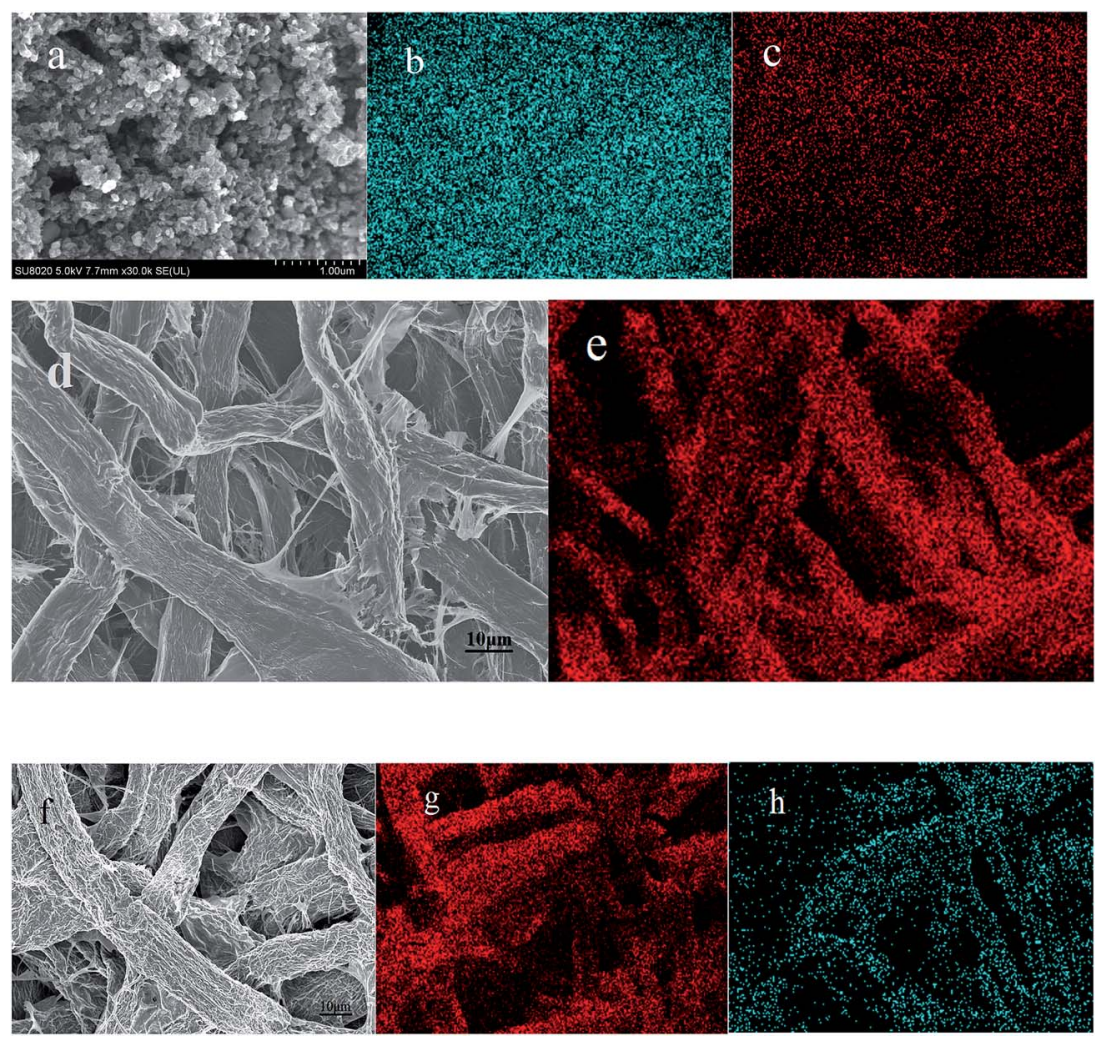

Fig. 4 FESEM patterns of S-AC, CF1 and CF2 (a) morphology of S-AC cathode material, (b) distribution of S and (c) C in S-AC, (d) morphology of CF1, (e) distribution of C in CF1, (f) morphology of CF2, (g) distribution of $\mathrm{C}$ and (h) $\mathrm{Al}$ in CF2.

S/AC are the least in the three batteries, revealing polarization and a low reductive reaction speed. ${ }^{29}$ In comparison, the CV curve of $\mathrm{S} / \mathrm{AC} / \mathrm{CF} 2$ exhibits the greatest peak currents and largest areas of the oxidation and reduction peaks, showing the least polarization and best electrochemical properties in three batteries. ${ }^{30}$ The results of EIS and CV tests illustrate that the deposition of $\mathrm{Al}$ on the surface of carbon interlayer can improve the conductivity, reduce the polarization and retard shuttle effect to a certain degree.

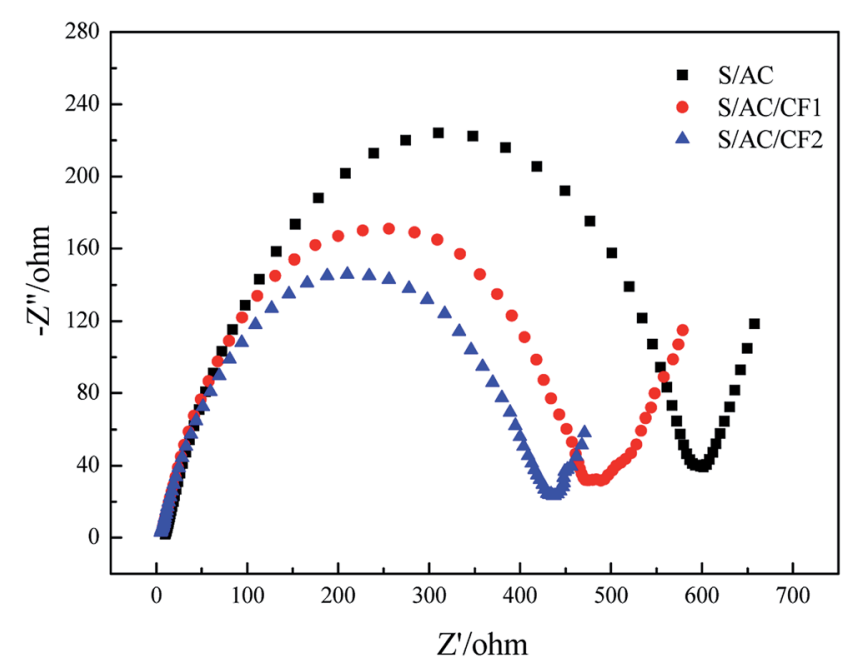

Fig. 5 EIS of S/AC, S/AC/CF1 and S/AC/CF2.
Fig. 7 describes the 1st, 100th and 200th charge and discharge characteristics of S/AC, S/AC/CF1 and S/AC/CF2 at the rate of $0.5 \mathrm{C}$ and $1 \mathrm{C}$. Compared to the stable discharge curves and plump discharging plateaus of the batteries with carbon films, especially S/AC/CF2, S/AC presents unconspicuous plateaus and rapid-declining discharging curves, manifesting evident electrochemical polarization and shuttle effect. ${ }^{31}$ The discharging platforms of S/AC/CF1 and S/AC/CF2 occur at about

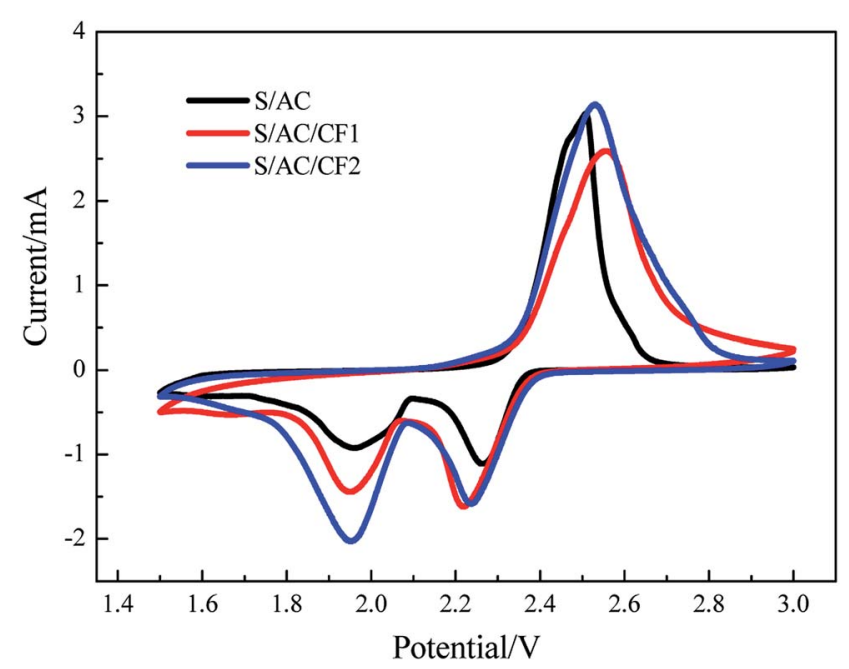

Fig. 6 CV profiles of S/AC, S/AC/CF1 and S/AC/CF2. 

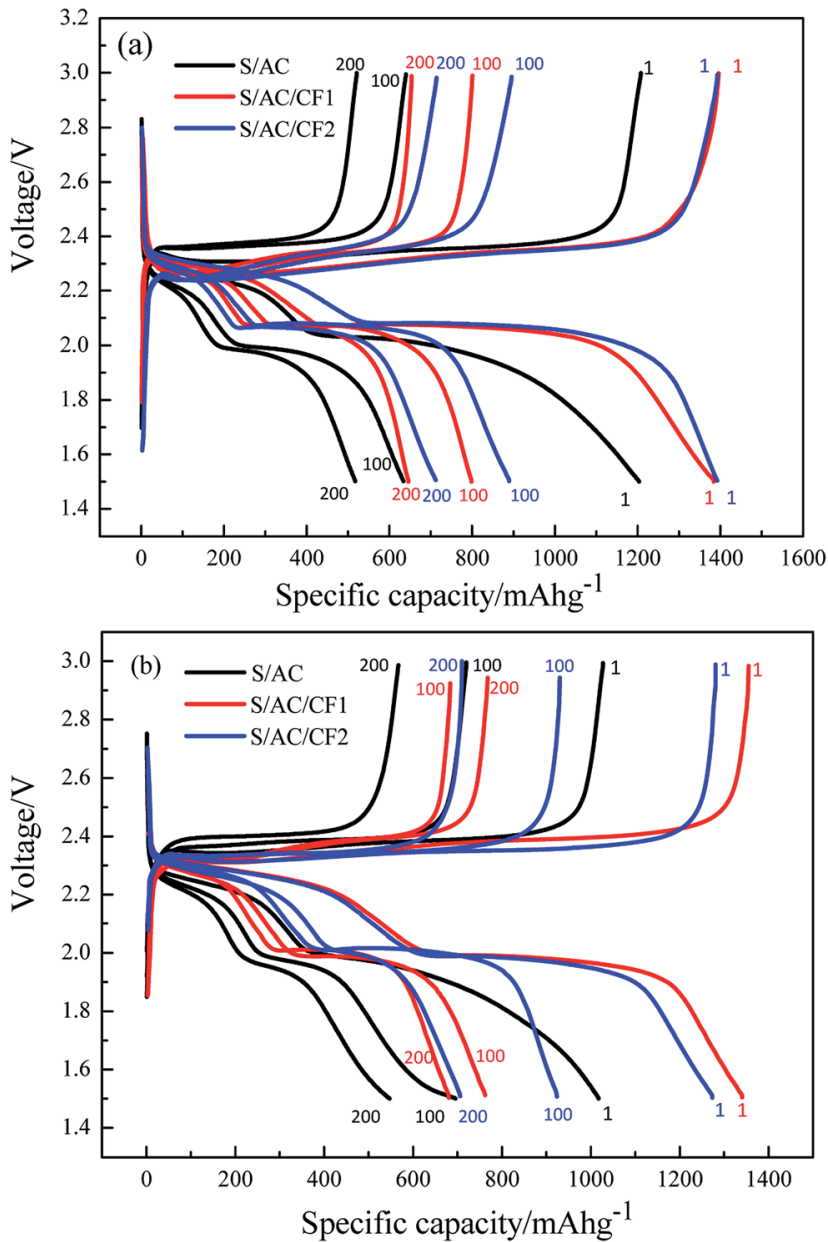

Fig. 7 The charge and discharge characteristics of S/AC, S/AC/CF1 and S/AC/CF2, (a) 0.5C, (b) $1 \mathrm{C}$.

2.3 V and 2.0-2.1 V respectively, higher than those of S/AC, which proves that the network structure of carbon interlayers can significantly improve the conductivity of the electrodes and effectively prevent polysulfides from diffusing to lithium anode. At $1 \mathrm{C}$ rate, $\mathrm{S} / \mathrm{AC} / \mathrm{CF} 1$ presents an initial specific capacity of $1341 \mathrm{~mA} \mathrm{~h} \mathrm{~g}^{-1}$, superior to $1273 \mathrm{~mA} \mathrm{~h} \mathrm{~g}{ }^{-1}$ of S/AC/CF2, but suffered from greater attenuation rate than $\mathrm{S} / \mathrm{AC} / \mathrm{CF} 2$. The reason may lies in two aspects, the specific conductance and malleability of $\mathrm{Al}$ on the surface of $\mathrm{CF} 2$, which may lead to excellent electrical conductivity and better mechanical strength of the interlayer thus enhance the utilization of the active material and sustain the volume expansion caused by the generation and deposition of polysulfides. ${ }^{32}$ Therefore, S/AC/CF2 should be considered to precede the other two batteries as far as the reversible capacity and cycling stability are concerned.

The specific discharge capacity and coulombic efficiency of three batteries are delineated in Fig. 8. Despite the fact that the coulombic efficiency of the three samples all precede $97 \%$ even after 200 cycles, conspicuous decrease occurs in the curves of $\mathrm{S} / \mathrm{AC}$ after 150 cycles at $0.5 \mathrm{C}$, and 100 cycles at $1 \mathrm{C}$, whereas S/AC/ CF2 exhibits the most stable curves of coulombic efficiency indicating the best cyclic reversibility and stationarity which are
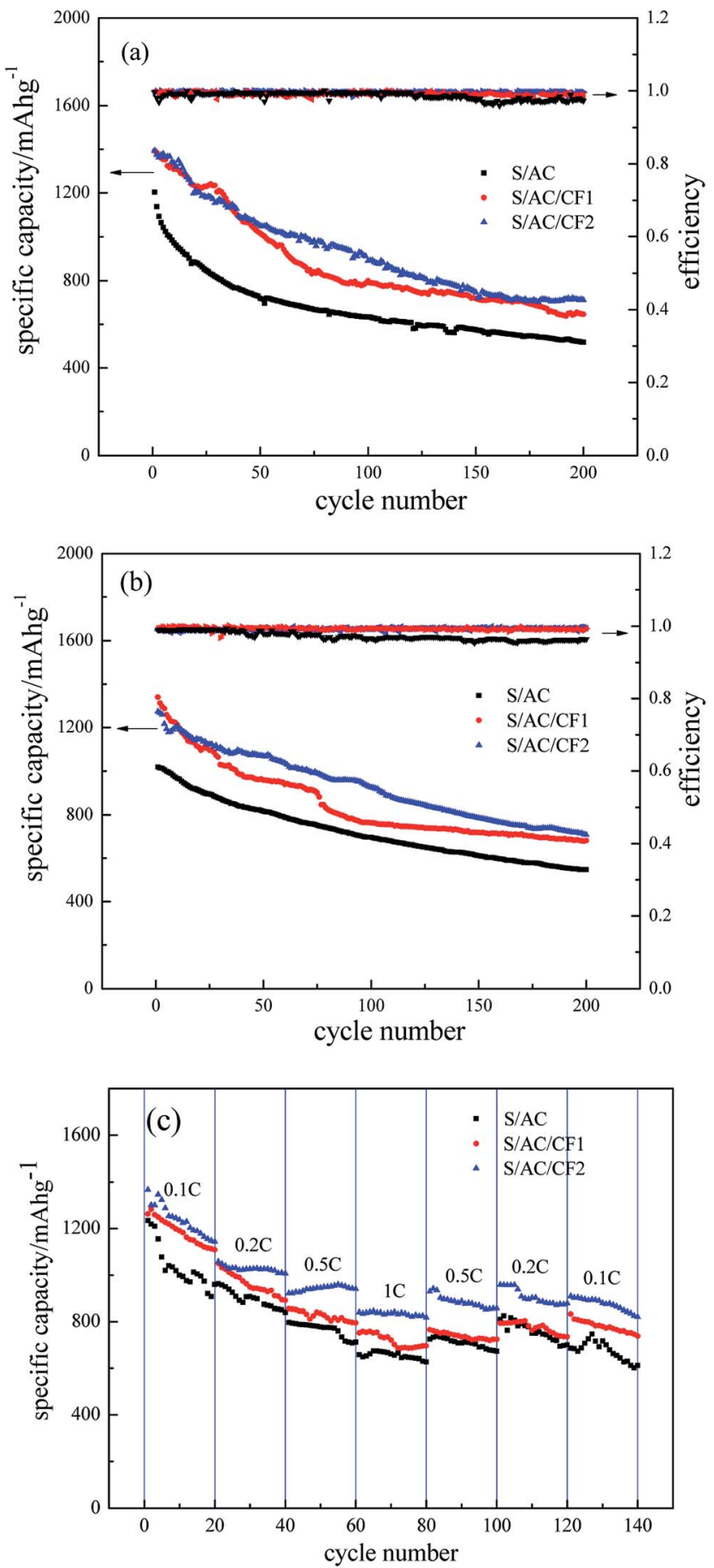

Fig. 8 Specific capacity and coulombic efficiency curves of S/AC, S/AC/CF1 and S/AC/CF2, (a) 0.5C, (b) 1C, (c) variable rates.

also confirmed by Fig. 8(c). The initial discharging specific

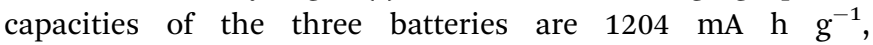
$1392 \mathrm{~mA} \mathrm{~h} \mathrm{~g}^{-1}$ and $1394 \mathrm{~mA} \mathrm{~h} \mathrm{~g}^{-1}$ under $0.5 \mathrm{C}$, and the specific capacities after 100 cycles are $634 \mathrm{~mA} \mathrm{~h} \mathrm{~g}^{-1}, 799 \mathrm{~mA} \mathrm{~h} \mathrm{~g}^{-1}$ and $889 \mathrm{~mA} \mathrm{~h} \mathrm{~g}^{-1}$ respectively. At the rate of $1 \mathrm{C}, \mathrm{S} / \mathrm{AC} / \mathrm{CF} 2$ produces a specific capacity of $924 \mathrm{~mA} \mathrm{~h} \mathrm{~g}^{-1}$ in the 100th cycle representing excellent retention rate. Compared to the specific capacity retention at $0.5 \mathrm{C}$, the higher one at $1 \mathrm{C}$ may be a direct 
result of the higher charge and discharge rate, which leads to insufficient time for polysulfides to dissolve and diffuse to lithium anode thus alleviates the passivation of lithium and the shuttle effect. The decline of capacity retention ratio after about 100 cycles may reflect the aggravation of electrochemical polarization and recession of the interception effect of the carbon interlayers, which may be associated with the fact that the precipitation and deposition of $S$ and polysulfides onto the carbon interlayer increased the viscosity of the electrolyte and reduced the migration rate of the ions. ${ }^{33}$ In Fig. 8(c), S/AC/CF2 provide an initial specific capacity of $1366 \mathrm{~mA} \mathrm{~h} \mathrm{~g}^{-1}$ at $0.1 \mathrm{C}$ and $821 \mathrm{~mA} \mathrm{~h} \mathrm{~g}^{-1}$ after 140th cycle under variable rates, which indicates that CF2 can efficiently improve the cycle reversibility. Experimental results demonstrate that, besides enhancing the electronic conductivity of the battery ascribing the specific conductance of $\mathrm{Al}, \mathrm{CF} 2$ can effectively impede polysulfides from migrating to lithium anode by the network structure thus assuage the passivation of lithium, as well as sustain the volume expansion of polysulfides by the improved mechanical strength profiting from the excellent malleability of $\mathrm{Al}$, which may be the major cause of the best electrochemical performance of S/AC/ CF2 among the three samples.

\section{Conclusions}

Conductive carbon interlayers were introduced into $\mathrm{Li}-\mathrm{S}$ batteries, prepared by heating filter paper and modified by magnetron sputtering. The carbon interlayer coated by $\mathrm{Al}$ film reduced the internal resistance and raised the utilization of sulfur effectively. The button cell S/AC/CF2 delivered $1394 \mathrm{~mA} \mathrm{~h} \mathrm{~g}^{-1}$ and $1273 \mathrm{~mA} \mathrm{~h} \mathrm{~g}{ }^{-1}$ respectively in the first discharging at the current rate of $0.5 \mathrm{C}$ and $1 \mathrm{C}$, and $889 \mathrm{~mA} \mathrm{~h} \mathrm{~g}^{-1}$ and $924 \mathrm{~m} \mathrm{~A} \mathrm{~h} \mathrm{~g}^{-1}$ even after 100 cycles. The coulombic efficiency after 200 cycles is still over 95\%, showing excellent capacity retention rate and stable cycle performances. The results show that it is an effective method to coat $\mathrm{Al}$ thin films on the surface of carbon interlayer by magnetron sputtering for modification of Li-S battery.

\section{Acknowledgements}

The authors gratefully acknowledge the support of the "Student's Platform for Innovation and Entrepreneurship Training Program" of the Ministry of Education of China (No. 201710359071).

\section{References}

1 P. G. Bruce, S. A. Freunberger and L. J. Hardwick, Nat. Mater., 2012, 11, 19.

2 S. Evers and L. F. Nazar, Acc. Chem. Res., 2013, 46, 1135.

3 A. Fotouhi, D. J. Auger and K. Propp, Renewable Sustainable Energy Rev., 2016, 56, 1008.
4 L. Li, L. Y. Li and X. D. Guo, J. Solid State Electrochem., 2013, $17,115$.

5 B. Ding, C. Yuan and L. Shen, Chem.-Eur. J., 2013, 19, 1013. 6 S. Evers, T. Yim and L. F. Nazar, J. Phys. Chem. C, 2012, 116, 19653.

7 H. H. Nersisyan, S. H. Joo and B. U. Yoo, Carbon, 2016, 103, 255.

8 J. Qu, S. Lv and X. Peng, J. Alloys Compd., 2016, 671, 17.

9 S. D. Seo, C. Choi and D. W. Kim, Mater. Lett., 2016, 172, 116.

10 L. Y. Li, X. Liu and K. Zhu, J. Solid State Electrochem., 2015, $19,1$.

11 L. C. Smith, P. Malati and J. Fang, Mater. Horiz., 2015, 3, 137.

12 D. H. Wang, D. Xie and T. Yang, J. Power Sources, 2016, 313, 233.

13 H. Y. Lee, Y. Jung and S. Kim, J. Nanosci. Nanotechnol., 2016, 116, 2692.

14 Y. Zhang, Y. Zhao and Z. Bakenov, Ionics, 2014, 20, 1047.

15 Z. Zhang, G. Wang and Y. Lai, J. Alloys Compd., 2016, 663, 501.

16 W. Sun, X. Ou and X. Yue, Electrochim. Acta, 2016, 207, 198.

17 Y. Yang, W. Sun and J. Zhang, Electrochim. Acta, 2016, 209, 691.

18 A. Manthiram and Y. S. Su, US 20140050973 A1[P]. 2014.

19 S. Li, G. Ren and M. N. F. Hoque, Appl. Surf. Sci., 2016, 396, 637.

20 Y. Huang, H. Li and M. Zuo, J. Magn. Magn. Mater., 2016, 409, 39.

21 L. Tao, H. Li and J. Shen, J. Magn. Magn. Mater., 2015, 375, 124.

22 J. Zhang, H. Li and Q. Tang, RSC Adv., 2016, 6, 114447.

23 Z. Hu, Modified Solid State Electrolyte Membrane for Lithium/ Sulfur batteries [D]. National University of Defense Technology, Changsha, 2011.

24 T. Li, X. Yang and Z. Xu, Aerosp. Mater. Technol., 2009, 39, 76.

25 H. R. Yang, X. R. Liu and J. H. Yang, J. Shanghai Inst. Chem. Technol., 2007, 1, 69.

26 M. Wang, H. Zhang and Y. Zhang, J. Solid State Electrochem., 2013, 17, 2243.

27 J. Brückner, S. Thieme and H. T. Grossmann, J. Power Sources, 2014, 268, 82.

28 Z. Deng, Z. Zhang and Y. Lai, J. Electrochem. Soc., 2013, 160, A553.

29 S. H. Chung and A. Manthiram, Electrochim. Acta, 2013, 107, 569.

30 Y. V. Mikhaylik, J. R. Akridge and N. White, Solid State Ionics, 2004, 175, 243.

31 S. Xiong, X. Kai and X. Hong, J. Natl. Univ. Def. Technol., 2012, 34, 150.

32 Y. S. Su and A. Manthiram, Chem. Commun., 2012, 48, 8817. 33 J. Yu, M. Zhang and F. Ding, J. Electrochem. Soc., 2014, 20, 105. 